\title{
LOS AMIGOS DE MIS AMIGOS SON MIS AMIGOS. PODER Y CORRUPCIÓN EN LA ARGENTINA DE CARLOS MENEM
}

\author{
Marc Hufty* \\ Instituto Universitario de Estudios del \\ Desarrollo, Ginebra
}

\begin{abstract}
No sé si los peronistas son corruptos o cleptómanos. Pasan al lado de una mesa, ven un cenicero y se lo llevan. Y luego ven 300 millones y también se los meten en el bolsillo. Es un fenómeno que todavía no se ha estudiado debidamente.
\end{abstract}

Jacobo Timerman, La Nación, 29 septiembre 1996.

En teoría, un Estado que pasa de un régimen político autoritario a un régimen democrático y de una economía estatal a una economía de mercado, debería constatar una disminución de su nivel global de corrupción. La reputación de la democratización es la de tener un efecto negativo sobre la corrupción. Diversas son las razones que explican este hecho: independencia del poder judicial, libertad de prensa, imputabilidad de los servicios públicos, transparencia en las decisiones y los procedimientos políticos.

* Agradezco mucho a María Cristina Baquero por su ayuda en la traducción y a Giorgio Blundo por sus comentarios. 
De igual manera, la liberalización económica, asociada al establecimiento de reglas uniformes y claras, poniendo fin a monopolios e introduciendo con prioridad la concurrencia, tiene la reputación de disminuir la incitación a la corrupción. Este principio corroborado por observaciones empíricas, es también, la conclusión a la que llegan Ades y Di Telia ${ }^{1}$ : "Los efectos de la apertura [la parte de importaciones en el producto interior bruto] sobre la corrupción son a la vez negativos e importantes."

¿Cómo explicar entonces un caso como el de Argentina, caso en el cual se retomó a la democracia en 1983 y en el que la liberación económica ${ }^{2}$ no ha, en apariencia, acarreado una disminución de la corrupción? Argentina, en efecto, ha sido regulamente citada como un país donde la conTipción ha constituido, además de una práctica corriente, un fenómeno en aumento, en particular bajo el mando de Carlos Saúl Menem, presidente de la República Argentina entre 1989 y 1999. En 1996, este país ocupaba el puesto 35 en el rango del Transparency International Ranking. En 1997, pasaba al 42 y en 1998 al 68, sobre 85 países considerados, con una nota de 3,0 sobre $10 .^{3}$ Para la población de este país, esta situación es igualmente preocupante, y es lo que reflejan los sondeos de opinión: en 1996, 81\% de las personas interrogadas estaban convencidas de la existencia de una mafia ligada al poder político. ${ }^{4}$ Según Gallup, en 1996,96\% de la población opinaba que el nivel de corrupción estaba elevado (30\%) o muy elevado (66\%), y desde 1990 la corrupción estaba mencionada regularmente como uno de los tres principales problemas del país, junto con el desempleo y los problemas de crecimiento económico. ${ }^{5}$.

1 A. Ades y R. Di Telia. "The causes and consequences of corruption", IOS Bulletin, 27 (2), April 1996. p. 8.

2 Ver M. Hufty, "Argentina: the great opcning up", G. Mace y J.-Ph. Thérien (cds.), Foreign Policy and Regionalism in the Americas, Boulder, Lynne Rienner Publishers, 1996, pp. 159-179, así como M. Hufty, "50 années de reformes économiques en ArgentineT G. Elienne, y J. Revel-Mouroz, (eds.). Economies d'Asie et d'Amérique latine: changements de cap, Genéve, Olizane (CRAM/ Etudes orientales/ 1HEAL), 1993, pp. 100-124.

3 Esta clasificación mide la percepción del nivel de corrupción por los negociantes extranjeros. Una nota de 1 O significaría una ausencia total de corrupción.

${ }^{4}$ The Economist, "Argentina: Cavallo strikes'", 26 de octubre de 1996. La mafia, originalmente concebida como un fenómeno específicamente siciliano, es una expresión utilizada por extensión, para designar toda organización criminal de una cierta importancia, estructurada e infiltrada en el seno de la autoridad política por la corrupción.

${ }^{5}$ M. Carballo de Cilley, "Encuesta nacional: La voz de la gente", G Beliz (comp.), No Robarás. ¿Es posible ganarle a la corrupción?, Buenos Aires, Ed. de Belgrano, 1997, pp. 191-230. 
Un elemento de respuesta a esta anomalía es ofrecido por lo que Harris-White y White califican de "nueva comupción." ${ }^{6}$ Si el autoritarismo y el dirigismo económico favorecen la corrupción a partir del reino de lo arbitrario y la opacidad de las reglas, la liberalización y la democratización no disminuyen necesariamente el nivel global de corrupción. Todo depende de la dinámica que entra en juego en los momentos de transición, momentos en los cuales los sistemas de control se debilitan y la incertidumbre jurídica o administrativa se generaliza. De una parte, del lado de la oferta, es posible que la corrupción se desplace hacia el sector privado. Aparecen nuevas elites, ligadas al mercado o mañosas, interviniendo en su debido tiempo, ante un Estado que permanece como principal regulador, con la intención de obtener ventajas económicas. De otra parte, del lado de la demanda, la concurrencia entre los partidos políticos, ligada a la democratización, acarrea necesidades financieras considerables. En sistemas políticos inestables, puede ser tentador para las nuevas elites políticas, sabiendo que no se quedarán en el poder sino por un periodo relativamente corto, aprovechar al máximo su paso por el control del Estado para enriquecerse.

Una objeción posible a esta tesis, estaría en la importancia que recientemente se ha acordado a la corrupción o más precisamente a su más grande visibilidad, lo cual a la vez, tendría su origen en el hecho de que los otros problemas, precedentemente más urgentes, inestabilidad política y económica, se han venido atenuando o que el fenómeno de la corrupción es actualmente puesto en evidencia por una prensa más libre y por unas instituciones más transparentes. ${ }^{7}$ ¿Es éste el caso de Argentina? ¿Cuál fue la naturaleza y la amplitud de la corrupción en el gobierno de Carlos Menem? y ¿Cuál la implicación del gobierno y de su presidente? Responderé a estos interrogantes en cuatro puntos.

En primer lugar, la corrupción es antigua en Argentina, y está estrechamente ligada a sus tradiciones en materia de gestión pública. Cualquiera que sea el tipo de régimen político, esta tradición se ha mantenido, en gran parte, gracias a la importancia del sitio que ocupa el Estado en la economía y de la excesiva reglamentación para el desarrollo de la actividad económica, lo que en consecuencia ha generado, una verdadera industria del fraude y una cultura de la corrupción.

${ }^{6}$ B. Harris-White y G. White, "Introduction", IDS Biilletin, 27 (2), April 1996, pp. 1-5.

${ }^{7}$ Ver por ejemplo: I. Massum. Menem: cirugía sin anestesia. Buenos Aires. Ed. Métodos. 1999, pp. |245 y ss. 
En segundo lugar, si la democratización y la apertura económica en Argentina, han efectivamente disminuido la "pequeña corrupción", el soborno que tocaba pagar para obtener una línea telefónica por ejemplo, la corrupción se ha concentrando hacia lo alto y ha alcanzado un nivel sin precedentes. La política se ha convertido en el medio más rápido de enriquecerse. De hecho, entre más se asciende en la jerarquía, más numerosas parecen ser las ocasiones de hacer "negocios" y más importantes aún las cantidades de dinero implicadas.

En tercer lugar, esto se explica gracias a la naturaleza misma del sistema político argentino y del partido en el poder entre 1989 y 1999, caracterizado más por el uso de relaciones patrimoniales y clientelistas? que por una gestión de tipo racional legal, como por la ausencia total de escrúpulos de sus dirigentes. Por fin, esta frágil moralidad, esta ausencia aparente de ética en la gestión pública, ha sido asociada a una impunidad casi absoluta, permitida por un control del ejecutivo sobre los poderes judicial y legislativo, así como sobre los "eventuales" órganos de control administrativos y policiales.

\section{CORRUPCIÓN}

¿De qué se habla exactamente?. En su sentido más amplio (y para ser simple), la corrupción política puede ser definida como todo uso ilegal o inmoral del poder y de la influencia ligadas a una función pública, con el objetivo de obtener una ganancia personal. Ella implica obligatoriamente tres actores: el corrupto, el corruptor y la paite perjudicada. El primero es aquel que intercambia ciertos recursos públicos que él controla con una ganancia privada, económica o no, el segundo se aprovecha ilícitamente de recursos públicos en intercambio con el pago de un soborno y la parte perjudicada es el Estado y/o el conjunto de la colectividad. ${ }^{9}$ A partir de esta definición, no es difícil concluir que los dos primeros actores realizan una ganancia neta, y que el tercero sufre una pérdida neta.

\footnotetext{
${ }^{8}$ El patrimonialismo es un fenómeno en el cual un soberano no hace distinción entre sus bienes privada y aquellos del listado que él encarna. El clientelismo es una relación de dependencia personal que se base en el intercambio recíproco pero desigual de recursos: a cambio de favores o de protección, el cliente ofrece al patrón su obediencia o sus servicios.

9 Para una discusión sobre las definiciones de la corrupción política, consultar: "Terms, concepts an: definition: an introduction", A. J. Heidenheimer, M. Johnston y V. T. LeVine, (eds.). Política'. Corruption, a Handbook, New Brunswick, Transaction Publishers, 1989, pp. 3-14.
} 
Aunque la corrupción sea castigada por la ley, ${ }^{10}$ resulta extremadamente difícil delimitar legalmente una frontera. Su definición legal, no es generalmente ni precisa, ni consistente, ${ }^{11}$ lo que deja un importante margen de maniobra interpretativa a lo judicial. Además, lo que es reprensible legalmente no lo es siempre en los hechos: la aplicación de la ley tiene en cuenta la moral, la legitimidad y la práctica. La corrupción conoce por lo tanto, varios grados, yendo de una corrupción percibida como benigna y tolerada hasta un crimen unánimemente reprobado, pasando por una "zona gris" en la cual las interpretaciones y la tolerancia varían en función de las circunstancias. Recientemente, el financiamiento de partidos políticos ha dado lugar a un debate sobre los límites de esta zona gris en varios países. Un consenso tácito se ha establecido entre las elites políticas para distinguir la corrupción en vista de financiar las actividades electorales de los partidos políticos, "desganadamente" reprimida, de aquella que tiene por único objetivo el enriquecimiento personal y que es severamente juzgada. La expresión célebre del ministro del Interior argentino Manzano (destituido de sus funciones en diciembre de 1992) "Robo para la corona", ilustra perfectamente esta ambigüedad. Hubiera podido añadir: "yo soy corrupto, es verdad, pero esta corrupción es benigna puesto que sirve para financiar las actividades del gobierno, y en consecuencia, tiene por objetivo final el bien público."

Fuera del sofisma contenido en ese razonamiento, la corrupción política, no es siempre un simple fenómeno ligado a ganancias económicas directas. Desde el punto de vista funcionalista, para los actores exteriores al Estado, representa un medio para influenciar las políticas públicas. Por intermedio de una retribución, ellos obtienen sobre la formulación de estas políticas públicas (decisión, aplicación de leyes y reglamentos, atribución de mercados) una influencia que no hubieran tenido, siguiendo los procedimientos normales. En razón a que este fenómeno de la corrupción es conocido y que la concurrencia recurre a ella por temor a perder ventajas, puede considerársele como un verdadero mercado negro o gris en el cual se intercambian bienes y servicios.

10 No siempre, por ejemplo en Suiza, la corrupción de funcionarios extranjeros por una empresa suiza para ganar un mercado es no solamente legal, sino deduciblc de impuestos, lo que parece lógico desde un cierto punto de vista, aunque cínico, ya que se trata de gastos de representación y que la concurrencia reacciona de la misma manera, aunque sin reconocerlo. Una adaptación de la legislación suiza a las normas de la OCDE está, sin embargo, en curso.

11 D. H. Lowenstein, "Political bribery and the intermedíate theory of politics", UCLA Law Review. 32, 1985. pp. 705-806. 
La corrupción es en consecuencia, imposible de reducir ajuicios simplistas. Desde un punto de vista positivo, puede favorecer el crecimiento económico, tal como se afirma en un enfoque teórico cercano a aquel de la modernización, ${ }^{12}$ e ilustrado por el estudio bien conocido de Fernando de Soto sobre el caso peruano. ${ }^{13}$ Los trámites legales para obtener un permiso de construcción o formalizar la existencia de una empresa, eran tan largos y costosos que la mayoría de las personas recurrían al mercado informal y a la corrupción. En este caso, la corrupción genera dinamismo económico, convirtiéndose en una alternativa necesaria a una reglamentación que paraliza la iniciativa y la innovación. Desde el punto de vista negativo, este tipo de mercado negro o gris no tiene absolutamente nada de transparente, funciona por redes personales, se basa en un acceso diferencial a la información y la disponibilidad de recursos necesarios a la corrupción. Resulta un mercado cartelizado y reservado a actores que controlan este tipo de actividades. Si se acepta el postulado de que en el mercado abierto, el productor más eficiente gana, la corrupción puede constituir una importante fuente de distorsión de los mecanismos económicos, perjudicando de manera evidente a los "inocentes" que persistirían en la honestidad y de manera general a la sociedad política, impidiendo funcionar los mecanismos de regulación democráticos y acentuando las desigualdades sociales. La corrupción es en consecuencia, una fuente de distorsión de los mecanismos políticos y económicos.

\section{UNA TRADICIÓN}

La corrupción es antigua en Argentina. Este país heredó, como los otros Estados de América Latina, tradiciones patrimoniales, corporativistas ${ }^{14}$ y militaristas hispánicas, lo cual favoreció las tendencias centralizadoras, autoritarias y clientelistas del sistema político. Como consecuencia, Argentina resultó ser una sociedad fuertemente estratificada y dotada de una economía fundada más sobre el pillaje, primero de los recursos naturales y luego del Estado, que sobre la inversión. A nivel administrativo, los puestos oficiales, son tradicionalmente fuentes de

12 N. H. Leff, "Economic development through bureaucratic corruption", American Behavioral Scientist-, 8(3), 1964, pp. 8-14.

13 F. de Soto. El otro sendero: La revolución informal, Lima, Instituto Libertad y Democracia, 1986.

14 El corporativismo es una doctrina política que pretende delegar la mediación política a los cuerpos civiles organizados (gremios, sindicatos, fuerzas armadas, Iglesia, etc.) 
enriquecimiento y son atribuidos mas por el tipo de relaciones que se tiene (amiguísimo) que por la competencia, lo que evidentemente favorece el clientelismo y la corrupción en detrimento del interés general.

Desde siempre en este país, la riqueza es asociada a la corrupción, el pillaje del Estado organizado por las clases dirigentes es inseparable de la corrupción de los funcionarios, es una tradición secular, a pesar de que sus mecanismos han variado con el tiempo. Al final del siglo XIX, el poder político y la economía estaban controlados por una oligarquía terrateniente. Una serie de montajes fraudulentos le permitió apropiarse de las mejores tierras de la pampa húmeda. Entre esos dispositivos se cuenta el de las cédulas ("cédulas de bonos de tierras"). En un primer momento, un banco hipotecario del Estado adquiere préstamos públicos en Londres. En un segundo tiempo, el banco presta este dinero bajo formas de bonos en pesos comentes a terratenientes que pueden comprar las nuevas tierras, quienes multiplican los préstamos sirviéndose de las tierras compradas como garantía y especulan más fácilmente a medida que su valor sube con la demanda. Una parte de la plusvalía realizada en esas maniobras es invertida en divisas, libras esterlina o pesos oro. En un tercer tiempo, el peso comente, que no es defendido por el gobierno argentino, sufre una devaluación, bajo el efecto de una emisión monetaria excedente. Como las cédulas son emitidas en pesos corrientes y no indexadas, basta esperar y reembolsarlas con la ayuda de las divisas ahorradas, para realizar jugosos beneficios. El Estado recupera la integridad del monto en pesos corrientes, pero debe reembolsar sus deudas internacionales en divisas. El conjunto de ciudadanos paga, en consecuencia, la deuda, pero la propiedad se encuentra cada vez más concentrada, evidentemente esta maniobra sería imposible de realizar sin la complicidad de las autoridades monetarias y políticas ${ }^{15}$.

"The number of fortunes built on the basis of mortgage bond speculation during the later 1880s was legión and included a varied cast of characters: wealthy land-owners, urban property owners, out-and-out speculators, politicians and bank directors. (...) The corruption became so widespread that, according to one report, the unscrupulous govemor of

\footnotetext{
${ }^{15}$ Ver H.S. Ferns. Britain and Argentina in the Nineteenth Century. Oxford. Clarendon Press, 1960; A. G. Ford, The Gold Standar. 1880-1914: Britain and Argentina, Oxford, Clarendon Press, 1962.
} 
the province of Buenos Aires, Máximo Paz, made a daily habit to ask the director of the provincial bank to his home to provide him with a list of people who were to be granted financial favors on the following day". 16

El sistema político quedó marcado no sólo por el caudillismo, esta personalización autoritaria de la política inmortalizada por la obra magistral de Sarmiento, Facundo, sino también por el "verticalismo", (un "centralismo democrático" versión local) que caracteriza el movimiento peronista (formalmente el Partido Justicialista), principal partido en Argentina desde 1946. El populismo, ese vínculo directo entre el líder y el pueblo que imita, omite y desvaloriza las instituciones políticas fue y sigue siendo una práctica de los principales partidos políticos. Estos atavismos del sistema político argentino tienen dos efectos principales: por una parte, las decisiones gubernamentales son aplicadas esencialmente por una autoridad en lugar de recurrir al consenso. Este hecho, en términos del análisis sistémico, limita fuertemente la función de los partidos políticos, interlocutores de las demandas políticas, y conduce sistemáticamente a una relación de fuerza; por otra parte, la extrema centralización del sistema político se cristaliza alrededor del presidente de la República, padre de la nación, árbitro supremo de los conflictos de interés, personaje central de la farándula, el circo mediático de la "corte" que gira alrededor del poder:

"Political power is concentrated to an enormous degree in the hands of a single individual, the president of the Argentine Republic. This situation is well understood not just by politically active groups and individuals but also by the average citizen (who quite frequently refers to the president as the government). (...) the president is considered both omnipotent and all-responsible, there is atendency for all political demands to be brought to him."17

Cualquiera que sea el tipo de régimen político y el partido en el poder, esta tradición se ha mantenido. El radical Hipólito Yrigoyen, primer presidente elegido en sufragio

\footnotetext{
${ }^{16}$ C. Damico, Buenos Aires, sus hombres, su política. ¡860-1890, México, 1891. citado por C. Manchal. A Century of Debí Grises in Latín America, Princelon, Princeton University Press, 1989, p. 136.

${ }^{17}$ P. G. Snow y G W. Wyrtia, "Argentina: Politics in a conflict society", H. J. Wiarda y H. F. Kline, Latín American Politics and Development, Boulder, Westview Press, 1990 (3". ed.), p. 161.
} 
universal en 1916, se contenta con administrar "el orden conservador"18 ${ }^{18}$ con los métodos tradicionales: cooptación, reciprocidad, caudillismo y clientelismo a todos los niveles. La atribución de cargos públicos a una amplia gama de partidarios políticos, se convierte en un elemento constitutivo del sistema político.

Los gobiernos de Juan Perón fueron objeto de numerosos escándalos, los cuales fueron revelados en su mayoría a posteriori. Los diputados que llegaron al poder con los bolsillos vacíos en 1946 se retiraron en 1955 con un patrimonio considerable. ${ }^{19}$ Los capitales ilegales, evacuados del país por los favoritos de régimen, están estimados en 2 o 3 mil millones de dólares y el mismo Perón habría poseído 700 millones de dólares US en una cuenta en Suiza. ${ }^{20}$ El gobierno peronista de 1973-76 será descrito, en los siguientes términos poco elogiosos, por un diputado de la oposición:

"El caos económico, el vacío de poder, la corrupción y la inmoralidad administrativa, el fraude político, el ahogamiento de las instituciones democráticas, el desprecio de derechos elementales y libertades, la malversación de fondos públicos, la confusión entre el partido y el gobierno, la aparición de la delincuencia en la cima del Estado, la complicidad sino la responsabilidad de altos funcionarios en las fechorías de ciertas bandas armadas que asesinan, torturan y secuestran impunemente los ciudadanos, forman un panorama que nunca antes había conocido la sociedad argentina." ${ }^{21}$

Los regímenes autoritarios, tradicionalmente justificados por los militares por la lucha contra la corrupción, no se salvan de acusaciones e implicaciones. Bajo la presidencia del general Videla (1976-81). una expansión espectacular del mercado financiero doméstico permite numerosas malversaciones, ${ }^{22}$ incluido en el seno del gobierno militar y en el entorno inmediato del ministro civil de la Economía

\footnotetext{
${ }^{18}$ Según una expresión de Natalio Botana. Ver D. Rock, El Radicalismo argentino, 1890-1930, Buenos Aires, Amorrortu, 1977.

19 L. M. Vega, Autopsie de Perón: Le bilan du péronisme, Duculot. Gembloux, 1974

20 P. H. Lewis, The Crisis qf Argentine Capitalism, Cliapel Hill, University of North Carolina Press, 1990.

21 Palabras de un dirigente de la UCR retomadas por A. Rouquie, "L'Argentine á l'heure militaire: la fin des llusions", Défense nationale, 32, juillet 1976, pp. 87-101, p. 87.

22 Una malversación es una falta grave cometida en el ejercicio de un mandato o de un cargo.
} 
(Hacienda), Martínez de la Hoz. ${ }^{23}$ Mientras que la deuda exterior aumenta a una velocidad vertiginosa, pasando de 8 a 36 mil millones de dólares en cinco años, los capitales en fuga suben en más de la mitad de los préstamos contraídos por el país. La corrupción y el pillaje de recursos del Estado se generalizan. En un campo, de por si considerado como una "vaca lechera" de la corrupción, aquel de los contratos del Estado para obras públicas y el abastecimiento a las empresas del Estado, el régimen militar pone en marcha una verdadera industria del fraude, calificada desde entonces de "patria contratista". Las principales empresas de este sector se constituyeron en un cartel, al seno del cual los precios de licitación pública estaban decididos según un principio de rotación de la empresa ganadora y la sobrefacturación de servicios, al beneficio de altos funcionarios cómplices y de los empresarios.

En general, el exceso de reglamentación de la actividad económica, ha multiplicado las oportunidades para situaciones de "renta". ${ }^{24}$ Se trata, por ejemplo, para un empresario de obtener restricciones de importación de productos que estarían en competencia con aquellos que él fabrica. En consecuencia, este empresario puede vender su producto a un costo superior, aunque su calidad sea inferior al que se encuentra en el mercado mundial, obteniendo así un jugoso excedente. Es así, que en Argentina se podía, hasta hace poco tiempo, comprar un carro de tecnología obsoleta al doble del precio del equivalente vendido en el mercado norteamericano o europeo.

De estas distorsiones estructurales resulta que es más rentable para los empresarios invertir "bajo el amparo" de los políticos con capacidad de decidir, utilizando redes y mecanismos de influencia para obtener una renta en detrimento de sus competidores, que mejorar su productividad. Las políticas públicas adoptadas reflejan en consecuencia, la capacidad de grupos de influenciar la burocracia y las autoridades en lugar de considerar el interés general. Una parte importante de la actividad de los partidos políticos, estrechamente ligados a intereses económicos,

\footnotetext{
${ }^{23}$ La revista Time ("Big profits in big bribery", Marzo 16 de 1981), clasificaba a la Argentina de los militares en el primer puesto de los gobiernos corruptos en el mundo. Martínez de Hoz fue procesado en varios casos después de 1983 sin que se probaran delitos en ninguna de estas causas. R. Di Telia. "Corrupción, competencia y eficiencia burocrática", G. Beliz (conip.), No robarás, pp. 319-352.

${ }^{24}$ O. Krueger. "The political economy of the rent-seeking society", The American Economic Review, 54(3), 1974, pp. 291-303.
} 
aspira, en consecuencia, a controlar la atribución de rentas, generando una práctica "politiquera", caracterizada por el clientelismo, el desvío de fondos, la prebenda, el tráfico de influencias y la prevaricación. ${ }^{25}$

\section{EL SISTEMA MENEM}

Este sistema alcanzó un nivel sin precedentes de corrupción durante los dos mandatos consecutivos de Carlos Menem (1989-95 y 1995-99). Mientras que se hubiera podido pensar que la liberalización a ultranza de la economía, las privatizaciones masivas y el cierre de la mayoría de las agencias gubernamentales, iba a tener un efecto negativo sobre la industria del fraude público, se ha producido en apariencia lo contrario.

Las privatizaciones, en parte emprendidas bajo el pretexto de disminuir las oportunidades de corrupción de funcionarios públicos, ${ }^{26}$ han dado ocasión para un gigantesco robo de los recursos del Estado. Aquí citamos en particular los casos de la compañía de aviación Aerolíneas Argentinas, del monopolio público de la telefónica Entel y del complejo petroquímico Bahía Blanca. El gobierno abrió licitaciones a principios de 1990 y adjudicó estas compañías a condiciones y precios que subestimaban de manera evidente su valor real en un contexto igualmente "turbio" y confuso. Además existen fuertes sospechas en cuanto al giro de sobornos a diversos miembros del gobierno implicados en la privatización de estas tres compañías, ${ }^{27}$ a pesar de las investigaciones judiciales y las revelaciones de la prensa, nadie ha sido condenado por estos casos.

$\overline{25}$ El desvío de fondos es la apropiación de fondos públicos por un funcionario. La prebenda es el provecho inmerecido, obtenido del ejercicio de un cargo público. El tráfico de influencias es el hecho de recibir un beneficio (monetario) por hacer aceptar bienes o servicios por el Estado. La prevaricación es una falta debida al no ejercicio de los deberes de un cargo.

26 A manera de anécdota, después de la privatización en 1990 de la compañía telefónica del Estado, Entel (deficitaria en decenas de millones de dólares), la primera preocupación de los nuevos propietarios fue la de hacer un inventario preciso de los empleados con ocasión de la primera paga: alrededor de mil empleados "fantasmas" no se presentaron nunca. La atribución de empleos ficticios -pero con salarios reales- fue y sigue siendo una de las especialidades de los servicios públicos argentinos. Están calificados de "ñoquis", según la receta italiana que se come tradicional mente el 30 del mes.

27 Ver por ejemplo A. Aramouni y A. Colombo. Críticas al líberal-menemismo, Buenos Aires, Fundación Proyectos para el Cambio, 1992: o A. Boceo y N. Minsburg, Privatizaciones: reestructuración del Estado y de la sociedad, Buenos Aires, Ed. Letras Buenas, 1991. 
Como lo afirmaba el presidente de la asociación de bancos extranjeros en Argentina, ${ }^{28}$ el país ha vivido bajo un régimen de cleptocracia donde toda transacción comercial importante implicaba "aceitar la maquinaria" con un soborno, "coima" o "mordida". ${ }^{29}$ Los casos de enriquecimiento sospechoso de funcionarios del gobierno de Menem son numerosos: entre otros, el procurador general de la nación, ${ }^{30}$ ministros, diputados y senadores, jueces, diversos jefes de servicio de policía y militares, se vieron implicados en "asuntos dudosos"; peor aún, mientras que los escándalos ligados a la corrupción han sido y son los temas número uno de la prensa día tras día, los responsables no han sido en ningún momento, ni interpelados ni castigados. Según una investigación de Noticias, sobre 108 funcionarios o amigos del gobierno acusados por corrupción entre 1989 y 1995, tres solamente fueron efectivamente condenados, figuras menores del régimen, sacrificados como chivos expiatorios. ${ }^{31}$ Los escándalos son tan numerosos, la impunidad tan generalizada y la ostentación de riqueza de esta "nueva elite" tan vulgar, que no se puede sino dudar entre la nausea o la rebelión.

La corrupción hizo paite integrante del sistema de poder en Argentina. La formación de Carlos Menem en gestión gubernamental se inició cuando ocupó el cargo de gobernador de la provincia de la Rioja, pequeña provincia árida pérdida al pie de la cordillera de los Andes y tierra del legendario caudillo Facundo Quiroga. El Noroeste argentino tiene la reputación de tener arraigadas las tradiciones políticas clientelistas, esto explica la proporción elevada, entre otras en la Rioja, de población activa empleada por los estados provinciales. El gobierno atribuye tradicionalmente puestos de trabajo como recompensa por los servicios prestados o como medida contra el desempleo. La corrupción es endémica y las instituciones de control están filtradas por los amigos del gobierno. Los fondos públicos, de los cuales la mayor parte viene del gobierno federal por el sistema de "coparticipación", son dilapidados por la elite política local.

Carlos Menem, elegido gobernador provincial (1973-76 y 1983-89), gracias al apoyo financiero de la familia de la esposa, los Yoma, contrajo en esta época deudas políticas que lo seguirían hasta la presidencia y desde ese entonces, se rodeó de algunas personas que lo acompañaron en su ascenso al poder. Con el

\footnotetext{
${ }^{28}$ Emilio Cárdenas, citado por G. Cerruti y S. Ciancaglini, El octavo circulo: crónica y entretelones de la Argentina menemista, Buenos Aires, Planeta, 1991, p. 255.

${ }^{29}$ L. Majul, Los dueños de la Argentina 77; los secretos del verdadero poder, Buenos Aires, Sudamericana. 1994

${ }^{30}$ Noticias, "Agüero Iturbide: el buen inversor", 17-08-1996.

${ }^{31}$ Noticias, "Las manos de la Justicia", 10-03-1996.
} 
riesgo de hacer un mal juego de palabras en cuanto a su origen Sirio y al apodo con el que le afligen sus detractores, Ali Baba, el gobierno de Carlos Menem se acercó más a un sultanismo, caracterizado por la generalización de una gestión patrimonial, de redes clientelares y nepotistas, ${ }^{32}$ que a un régimen legal-racional. Algunos ejemplos escogidos entre la multitud, dada la dimensión de sus impactos, demostrarán la gravedad de la situación.

\section{LAS REDES DE PODER MENEMISTAS}

Ante todo, es posible clasificar los personajes que giraban alrededor del presidente Menem con la ayuda del esquema no. 1, el cual, antes de pretender una exhaustividad científica, privilegia la perspectiva ilustrativa y divertida, entre otras, por el carácter subjetivo de la discusión. Los personajes pueden ser repartidos en nueve categorías (número arbitrario escogido por su simetría gráfica), ellas mismas reagrupadas en dos grandes grupos, el lado privado y el lado público y en tres niveles (círculos) de proximidad al jefe. Los individuos pueden encontrarse en varias categorías a la vez y pasar de una categoría a la otra o de un círculo al otro (la categoría "especiar', particular, no explícita en si, merece una explicación. Se trata de magos, adivinos y otros personajes extraños de los que Menem gustaba rodearse).

Si se toma como ejemplo el caso de María Julia Alsogaray, quien es hija de Alvaro Alsogaray, liberal cercano a los militares, muchas veces ministro y fundador de la Ucedé, pequeño partido liberal fagocitado por Menem en el momento de su llegada al poder. María Julia (ingeniera) pasó de un rango de aliada política coyuntural, empujada por su padre (circulo III categoría Políticas) en 1989, a aquel de encargada de la privatización de Entel (rango II, categoría Política). 1990, representa para ella, el año de su apogeo. Llegó a pertenecer al grupo restringido de favoritos del presidente (círculo I categoría Mujeres). Además fue tema de los medios de comunicación y de la farándula. Por citar un ejemplo, en uno de los números de la revista Noticias, aparece excesivamente llamativa luciendo "solamente" un elegante abrigo de piel. Puesta en tela de juicio su honestidad, al verse comprometida en algmios escándalos del régimen, desciende en 1993 (hasta 1999) al rango de secretaria del Estado en Medio Ambiente (círculo II categorías políticas) y "amiga" del presidente (círculo III categoría Mujeres).

${ }^{32}$ Noticias, «Las manos de la Justicia». 10-03-1996 


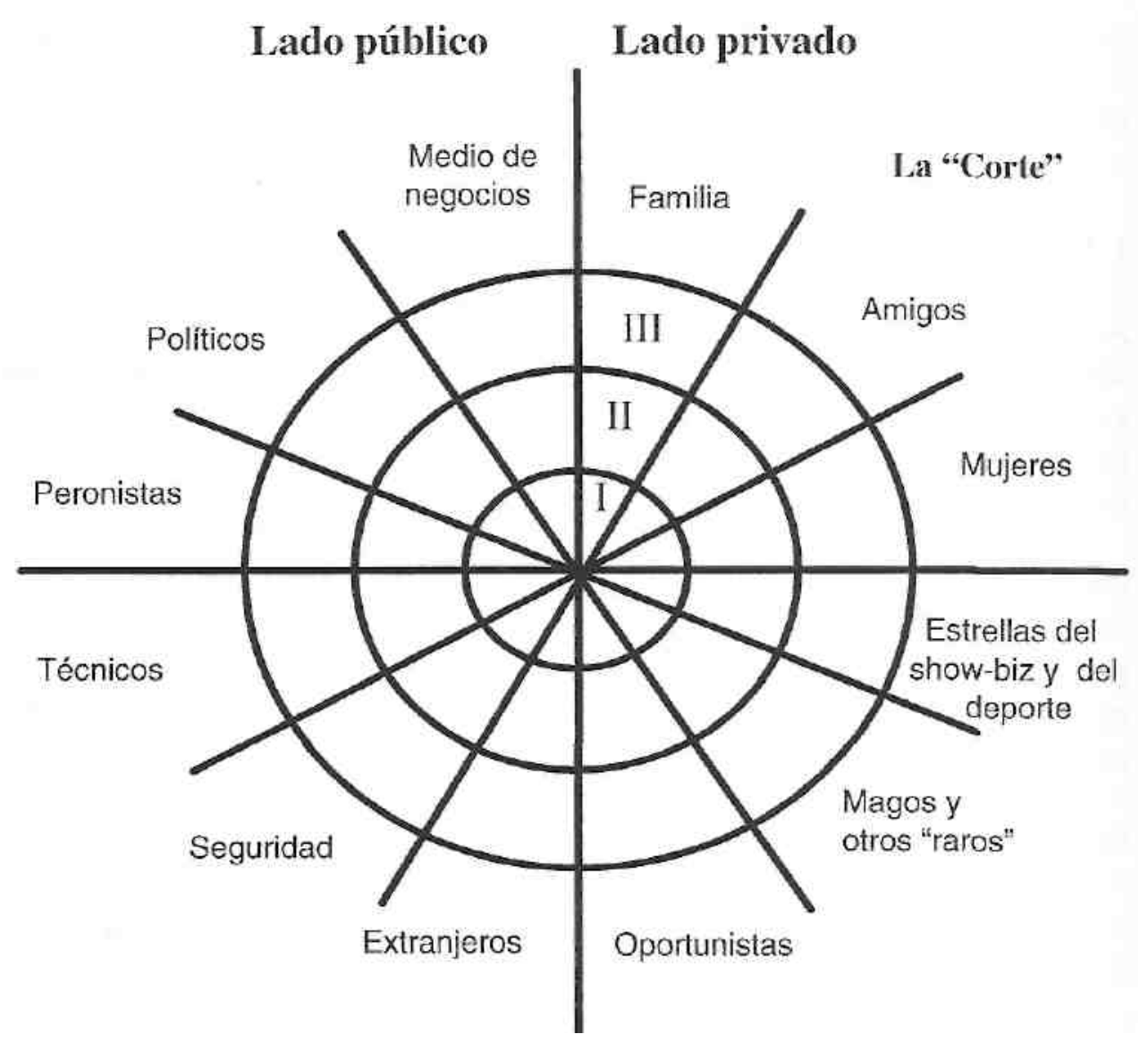

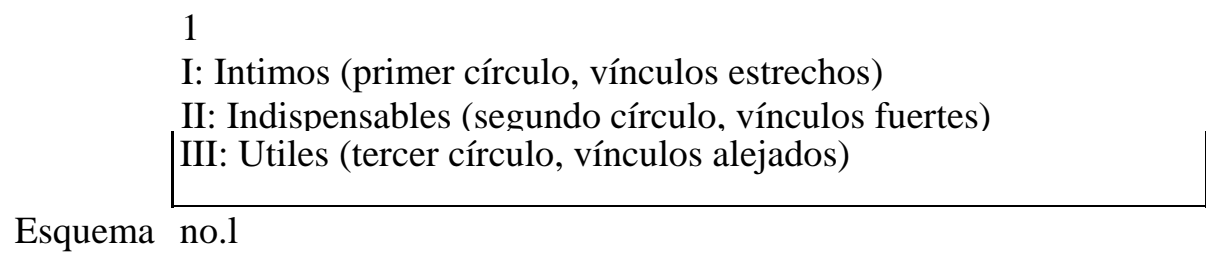




\section{EL CUÑADO}

Cuando Menem accede a la presidencia en 1989, debe, para pagar sus deudas políticas, acordar puestos de importancia a sus "amigos" y en particular a la familia Yoma, la cual obtiene varios puestos administrativos importantes, entre los que se cuenta la presidencia de la dirección de aduanas del aeropuerto de Ezeiza.

Este será el origen de un caso ejemplar, el caso Swift-Armour, uno de los primeros en ser objeto de una importante cobertura de los medios de comunicación, tanto por el alto nivel en que se desarrolla la corrupción como por el vínculo que demuestra entre el poder ejecutivo y los "negocios familiares". Propiedad de la firma estadounidense Campbell Soup, la empresa Swift-Armour es uno de los más antiguos frigoríficos (compañías exportadoras de carne) norteamericanos en Argentina. Con la generación de una cifra anual que gira alrededor de los 100 millones de dólares, se demuestra que es la primera exportadora agro-industrial del país. Deseosa de modernizar su producción, emprende en 1987 los trámites necesarios para importar una maquinaria por valor de 4.4 millones de dólares exentos de tasas, conforme a las leyes sobre la promoción industrial, destinadas a favorecer la modernización de la producción por la detaxación de importaciones de bienes de producción. Los trámites suponen una aprobación específica del poder ejecutivo, pero por razones de inestabilidad política, la autorización es aplazada hasta la elección del gobierno de Carlos Menem así que en 1990, Swift-Armour vuelve a la carga.

Por una razón misteriosa, el representante de la compañía es enviado de ministerio en ministerio y siempre con excusas variadas, hasta que el caso se esclarece. Bajo la "autorización" del presidente Menem, el ministro de la economía, Erman González (antiguo contable de la firma Yoma), confió la responsabilidad de los trámites en cuestión a Emir Yoma, cuñado de Carlos Menem, jefe del clan Yoma y consejero del presidente (círculo I Familia). Este último reclama secretamente a Swift-Armour 400.000 dólares para permitir la exención de tasas pedidas, o sea el equivalente de la suma que la compañía debía ahorrar. La compañía se encuentra entonces entre la espada y la pared, porque una vez la exención pedida, no es posible, según la ley argentina, retractarse y simplemente pagar las tasas. 
Es posible que si la suma exigida no hubiera sido tan elevada, la dirección argentina de Swift-Armour habría, como otras empresas, pagado el soborno y puesto fin a esta "película". Pero en lugar de pagar, la dirección hace un llamado al embajador de Estados Unidos en Argentina, Clarence Todman (Círculo II Extranjeros), quien aprovecha la visita del presidente Bush (Círculo I Extranjeros) ai país en diciembre de 1990, para que el caso sea presentado como un caso típico de los obstáculos para el desarrollo de buenas relaciones entre los dos países. Después de la intervención del ministro de Relaciones extranjeras de la época Domingo Cavallo (Círculo I políticos), el presidente Menem, muy preocupado de "agradar" a un poderoso intermediario, retira inmediatamente la gestión de este trámite de las manos de Emir Yoma y el problema se arregla en pocos días, sin el pago de ninguna "mordida".

La naturaleza de esta "autorización" presidencial es, por supuesto, uno de los puntos centrales de este caso, aunque sea difícilmente demostrable, puesto que los hechos sucedieron de manera privada y sin ningún rastro escrito. Según Horacio Verbitsky, ${ }^{33}$ el presidente dio explícitamente a Erman González la orden de confiar la gestión de los trámites de Swift-Armour a Emir Yoma. Así mismo, es imposible pensar que, en un contexto de concentración extrema del poder, por parte del ejecutivo, el presidente no haya sido informado de todo lo que estaba sucediendo. Las lecciones del caso Swift-Armour son instructivas: ciertos derechos garantizados por la ley, dependían para su aplicación, de lo arbitrario del poder ejecutivo y representan ocasiones favorables a la corrupción; esta involucra sumas importantes, estaba organizada al interior del más alto nivel del Estado; en fin, los asuntos privados y públicos estaban inextricablemente entremezclados.

La cantidad y la importancia de los escándalos en los cuales se mencionan los nombres de Emir Yoma y su familia, marcarán de manera significativa, por el hecho de que son personas cercanas a Menem, la presidencia: lavado de dinero sucio, tráfico de cocaína, tráfico de armas, tráfico de oro, sobrefacturación de abastecimiento al Estado y préstamos fraudulentos entre otros, serán algunos de los delitos realizados bajo este mandato.

\footnotetext{
${ }^{33}$ H. Verbitsky, Robo para la Corona: Los frutos prohibidos del árbol de la corrupción, Buenos Aires. Planeta, 1991, p. 11.
} 


\section{LA MEJOR POLICIA DEL MUNDO}

Los regímenes militares, en particular aquel de 1976-83, han dejado profundas huellas en las instituciones argentinas, particularmente en el cuerpo policial y de seguridad. Durante este oscuro periodo, todo tipo de excesos de poder estuvo permitido: arrestos arbitrarios, torturas, asesinatos, robo en los domicilios de las personas arrestadas. Ciertas bandas que se formaron durante estos años subsisten en la actualidad dentro del cuerpo de seguridad y perpetúan sus actividades. Lo que puede parecer una exageración o una caricatura y es lamentablemente una realidad ampliamente documentada, entre otras, por la cantidad no negligente de investigaciones y condenas de personas que, perteneciendo a estas instituciones han cometido actos criminales. El ciudadano argentino teme en general hacer un llamado a la policía y no le tiene, a menudo con razón, ninguna confianza.

La policía de la provincia de Buenos Aires es una de las instituciones señaladas por el ejercicio de un terrorismo de Estado. Esta provincia cuenta con 12 millones de habitantes. Su capital no es, contrariamente a lo que podría sugerir su nombre, la ciudad de Buenos Aires, sino la Plata, una pequeña ciudad, situada al sur de esta última. Sin embargo la geografía humana y económica de la provincia gira alrededor de esta megalópolis, puesto que los límites entre la provincia y la capital federal están constituidos por una de las principales arterias de la ciudad (Avenida General Paz), situándose por lo tanto en plena zona urbana. Las instituciones administrativas provinciales dirigen en consecuencia una parte importante de la ciudad de Buenos Aires, además de una multitud de ciudades provinciales. Esta policía de Buenos Aires estuvo implicada en un número impresionante de escándalos, yendo desde de la criminalidad organizada de tipo mafiosa, pasando por el atentando contra la AMIA (Asociación Mutual Israelita Argentina) que dejó 86 muertos, hasta el asesinato del fotógrafo de prensa José Luis Cabezas.

Eduardo Duhalde (circulo II Peronistas), gobernador de la provincia de Buenos Aires, cuando calificó la policía de la región como la "mejor policía del mundo", nunca se imaginó que posteriormente, a cada escándalo, que implicara a esta institución, los comentaristas retomarían esta frase con ironía. En 1999, frente a las múltiples presiones para mejorar el control de este cuerpo policial, un civil, el juez penal García Berro, fue nombrado auditor general del Oficio de control de corrupción y de abuso de función de la provincia. Anteriormente, las quejas que 
concernían la policía eran examinadas por la División de Asuntos Internos, administrada por las autoridades policiacas mismas. El nombramiento del auditor, que conllevaría aparentemente a un mejor control de la policía, debe, no obstante, ser tomado con prudencia puesto que el juez Berro está estrechamente ligado al ministro de lajusticia de la provincia, quien fue el que promocionó su candidatura, León Arslanian, el mismo, a su vez, antiguo ministro de lajusticia del gobierno Menem.

Recientemente han aparecido los "arrepentidos" a la moda italiana, quienes han roto el pacto de silencio, policías que decidieron denunciar la exacción de sus colegas, a pesar del riesgo que corrían sus vidas. Aceptaron testimoniar anónimamente a cambio de una protección física. Para ponerle cifras a este tipo de corrupción, se puede decir que las autoridades superiores de la policía federal, encargada de la seguridad de la ciudad de Buenos Aires, se vieron involucradas en negocios que aportaban mas de tres millones de dólares mensualmente ${ }^{34}$. Un policía, el cabo Marcelo Hawrylciw, denunció en 1998 la organización en su comisaría, de una red de chantajistas, controlada por los oficiales superiores incluidas las autoridades de control. Según él, las extorsiones hechas a vendedores ambulantes y de comercios, a los taxistas y a las prostitutas, proporcionaban un beneficio de 60.000 dólares mensualmente, los cuales eran repartidos hasta en las altas esferas de la jerarquía. Estos hechos fueron confirmados por varios de sus colegas $^{35}$ así como por asociaciones de vendedores ambulantes y de comerciantes, quienes precisaron que aún recientemente, era imposible proceder a una denuncia, pues las diferentes comisarías se apoyaban mutuamente y todo denunciante, se exponía a no poder trabajar nunca más en la ciudad de Buenos Aires. Lajusticia retiene aparentemente testimonios o pruebas (registros de pagos ilegales) que implican a 15 de 52 comisarías de la policía metropolitana ${ }^{36}$. Hawrylciw, por su parte, fue víctima después de su denuncio, a pesar de una protección permanente, de tres ataques armados.

Como siempre en estos casos, la batalla se desplazó hacia el campo de la justicia y lo político. Los policías incriminados disponen de diversas estrategias. Varios testigos mencionaron que las sumas de dinero recolectadas por los policías, son

34 "Podría truncarse la investigación por corrupción policial", La Nación, 13.3.99. H. ${ }^{35}$ Capiello, "Los testigos confirman casos de corrupción", La Nación, 21.10.98. L. 36 Zommer, "Más testimonios de corrupción policial", La Nación, 22.3.99. 
aportadas a partidos políticos en sus actividades clientelistas o en las campañas electorales. Por otro lado, con la intimidación directa de los jueces o de testigos, ellos pueden, en consecuencia, hacer intervenir los políticos para obtener ser juzgados por jueces "amigos" o para que un juicio desfavorable sea destruido en apelación, lo cual se produjo en numerosas ocasiones. ${ }^{37}$ Los policías, son simplemente puestos en libertad por "falta de pruebas" o en el peor de los casos ligeramente condenados. La estrategia de la administración ha sido, dada la multiplicación de los escándalos implicando la entidad federal, la de proceder a jubilaciones y a rotaciones en las comisarias, como una medida destinada antes que nada a calmar la opinión pública. ${ }^{38}$

\section{UN MONUMENTO A LA CORRUPCION}

La construcción del embalse de Yacyretá ha constituido un paroxismo del fraude organizado por los proveedores de bienes y servicios del Estado. Obra gigantesca situada entre Paraguay y Argentina y objeto de un tratado entre estos países, el embalse debe proporcionar, al terminar su construcción, más de 18 millones de kilovatios, o sea el 40\% de la energía eléctrica producida en Argentina. Su realización se ha extendido a todo lo largo del siglo XX; Los primeros proyectos datan de 1905. El acuerdo binacional que lanzó el proyecto fue firmado en 1973 por los generales Perón y Stroessner. El montaje financiero de la operación se efectúo desde 1978, en el régimen militar. En 1980, la firma francesa Dumez (Suez Lyonnaise des Eaux), ganaba el concurso de adjudicación de trabajos de ingeniería civil. En 1983 la firma italiana Impregilo, empresa de construcción de la familia Agnelli y perdedora de este mismo concurso, estuvo asociada de autoridad por el gobiemo argentino en Dumez para conformar un consorcio Eriday (Empresas Reunidas Impregilo-Dumez y Asociados para Yacyretá) contratista de trabajos iniciados en 1983 y que continuaron bajo la presidencia de Raúl Alfonsín.

Cuando Carlos Menem llegó al poder en 1989, caracterizó a Yacyretá con la célebre frase de "monumento a la corrupción" y declaró su voluntad de terminar con la obra. Sin embargo, frente al hecho de que parar la obra sería más costoso

\footnotetext{
37 C. Dutil y R. Ragendorfer. La Bonaerense, historia criminal de la policía de la provincia de Buenos Aires. Buenos Aires, Ed. Planeta. 1997.

38 F. Rodríguez, "Proceso de depuración en la Federal", La Nación, 21.10.98.
} 
que finalizarla, su gobierno no solamente continuó con los trabajos sino que la presidencia y sus círculos más cercanos, estuvieron interesados a tal punto, que ubicaron en diversos puestos de responsabilidad a personas cercanas al poder. Entre otras hacen parte del consorcio Eriday Francisco Macri (círculo II Medio de negocios), Amelia Fortabat (círculo I Medio de negocios) y Benito Roggio (círculo III Medio de negocios), tres de los empresarios más ricos del país y algunos de los que hicieron fortuna bajo el régimen militar y pertenecen a lo que se ha calificado de "patria contratista", empresas que se enriquecieron, aprovechando una situación de rentas ligadas a la provisión de bienes y servicios al Estado. Ellos se encuentran, en la actualidad, entre los próximos de Menem y contribuyeron a financiar las campañas electorales.

La primera de las 20 turbinas entró en función en 1994, con ocho años de retraso, la última en 1998. En lugar de mil millones y medio de dólares del presupuesto inicial, Yacyretá, se estima, habría costado mas de ocho mil millones ${ }^{19}$, de los cuales mil millones financiados por el Banco Mundial, 840 millones por el Banco Interamericano de Desarrollo y el resto por préstamos sobre el mercado privado de los capitales garantizados por la Argentina y reembolsados en parte por un impuesto de $7 \%$ sobre las facturas de electricidad de los consumidores argentinos. Una última fase del proyecto, estimada según las fuentes entre 750 millones y dos mil millones de dólares, debe permitir elevar el nivel de la retención de agua para obtener una producción de electricidad óptima.

Una parte del aumento de costos del embalse es debida a los plazos causados por los desórdenes políticos y económicos que Argentina ha conocido (los trabajos pararon en varias oportunidades) o a alzas de interés mundial. Otra parte es debida a la corrupción y a habituales mecanismos de pillaje de los recursos públicos. Este embalse es conocido en el Banco Mundial como "el embalse que financió la guerra de las Malvinas", se cree que los préstamos contratados por el régimen militar de 1976-83 para la construcción de Yacyretá, fueron en realidad utilizados para comprar armas. $^{40}$

\footnotetext{
${ }^{39}$ Las cifras varían de 8 a 13 millares según si se tiene en cuenta los trabajos estrictamente ligados al embalse o el conjunto de los costos directos o indirectos. Mientras que las medidas de acompañamiento ligadas al desplazamiento de la población y a medidas medioambientales previstas en el acuerdo de fmanciamiento con el Banco Mundial y el Banco Interamericano de Desarrollo no han sido todavía completamente respetadas, si el depósito del embalse pasa finalmente de 76 a 83 metros como ha sido previsto, los costos de medidas de acompañamiento aumentarán de 2 millares de dólares. Ver la World Rivers Review. February 1998. http: // www.im.org / pubs / wrr / 9802 / yacireta.html.

${ }^{40}$ Inter Press Service, World News, "Development: World Bank probes in-house eorruption", 16.7.96.
} 
Además del aumento de estos costos, el consorcio Eriday, reclama, después de la variación de las tasas de cambio, una actualización de costos, aunque esto implique la creación de normas jurídicas e indemnizaciones suplementarias entre otros. Estas reclamaciones, calificadas de "asuntos contractuales pendientes", doblaron entre 1997 y 1999, pasando de 770 millones a más de mil quinientos millones de dólares, en parte porque Eriday aplica una tasa de interés anual de 12\% sobre las indemnizaciones reclamadas. ${ }^{4}$ Los ministros de la Economía Cavallo y Rodríguez rechazaron la mayoría de las reclamaciones, así que la justicia y la dirección de la Entidad Binacional Yacyretá (EBY), encargada de administrar el proyecto, reconoce menos del 20\% de las solicitudes de Eriday. Pero en Argentina los litigios de este orden no se arreglan nunca según procedimientos legales. El presidente Menem tomó el caso personalmente y transfirió por decreto (47/99 del 29 de enero de 1999) el expediente del ministerio de la Economía al Secretariado presidencial, dirigido por Alberto Kohan (circulo I Amigos), un miembro de su "guardia cercana". Las reclamaciones de los consorcios fueron legitimadas por el Ejecutivo, pero las protestas de la oposición y los adversarios internos de Menem lo obligaron a cambiar de estrategia. Se conformó una comisión de arbitraje dentro de la cual se encuentra el ex secretario de Estados Unidos Henry Kissinger.

Un incidente traído a colación por Horacio Verbitsky ${ }^{42}$, ilustra los mecanismos del incremento fraudulento de los costos. El antiguo director ejecutivo de la Entidad binacional, responsable de la gestión del embalse, Osvaldo Torres, afirmó que Emir Yoma, exigió la compra de diez generadoras Siemens por Yacyretá a un precio fijado por él mismo. Siemens ya había ganado la licitación para el abastecimiento de estas generadoras, pero el precio del contrato propuesto por Yoma, recargaba esta oferta de 22 millones de dólares. Según Torres, en el transcurso de una reunión Yoma le habría precisado una clave de repartición de esta extra, clave que comprendía a Carlos Menem y a algunos de sus más cercanos colaboradores. Torres, chocado por estas exigencias, rechazó firmar el contrato e hizo un llamado directo al presidente Menem. Este último lo recibió en la compañía de Yoma, y como era de esperarse le clarificó sobre la inutilidad de su queja. Torres, bajo presión del entorno de Menem, se vio obligado a renunciar poco tiempo después.

\footnotetext{
41 "Yacyretá, otra vez en la mirada por mayores costos". La Nación. 18.3.99.

${ }^{42}$ H. Verbitsky, "El asilo al jinete bonsai"; Página 12, 4.4.99. El título extraño de este artículo hace referencia a la baja estatura del general Lino César Oviedo.
} 
Como consecuencia de la subida vertiginosa del costo del embalse, la electricidad producida costará 0,095 dólares de kilovatio-hora, mientras que actualmente se vende a 0,03 en Argentina. Para considerar la instalación como rentable, en particular con la perspectiva de una privatización, habría que disociar el costo financiero del valor de la producción eléctrica, pasando los sobrecostos a las pérdidas y beneficios de las cuentas nacionales del país. Una serie de incidentes ligados al funcionamiento del embalse no contribuyen a solucionar este asunto. A comienzos de 1999, algunos problemas han sido detectados en cinco turbinas de tipo Kaplan, las cuales son abastecidas por la empresa alemana Voith. Se ha interrumpido prematuramente su funcionamiento y a pesar de que las turbinas estaban aseguradas, hubo pérdidas ligadas a la interrupción de la producción de electricidad, estimadas a 50.000 dólares por día y por turbina parada.

Por otro lado, para una economía de talla modesta como la de Paraguay ${ }^{43}$ Yacyretá representa, también la "gallina de los huevos de oro". La empresa Conempa. propiedad del ex presidente Juan Carlos Wasmosy, le sirvió para acumular una verdadera fortuna, en parte ilegal. ${ }^{44}$ En el momento de la construcción del embalse de Itaipu, entre Brasil y Paraguay, posee una paite del consorcio Eriday. Wasmosy ha, en consecuencia, defendido personalmente las reclamaciones del consorcio, incluso cuando era presidente, haciendo presión para que el director argentino de la Entidad Binacional Yacyretá, Jorge Padreira, quien no reconocía las reclamaciones de Eriday, fuera reemplazado. ${ }^{45}$ Un abogado, antiguo asociado de Menem, Raúl Reali, lo reemplazó en febrero de 1999. El general Oviedo (Circulo I Extranjeros), hoy refugiado en Argentina, después de un arreglo de cuentas que condujo a comienzos de 1999 a la partida del presidente Raúl Cubas Grau, sucesor de Wasmosy y calificado de mañoso por el nuevo presidente de su país, ${ }^{46}$ tenía también, intereses personales en Yacyretá y una relación estrecha con Carlos Menem.

\footnotetext{
${ }^{43}$ Un PNB de 10 millares de dólares en 1997, o sea el 3\% del de Argentina, Banque Mondiale, Rapport sur le déve/oppement dans le monde, 1998-99.

${ }^{44}$ Según la República, diario de Montevideo, Uruguay, 12-14 de febrero de 1996, Conempa habría desviado 29 millones de dólares con ocasión de su participación en la construcción de Itaipú. No es probable que estos desvíos hayan sido realizados sin la participación de Stroessner y de los militares paraguayos. Ver C. Guibeleguiet, "Sur fond de trafics illicites et de corruption: le Paraguay á nouveau menacé par ses militaires", Le Monde diplomatique, juin 1996, p. 21. Itaipú es también considerado como el monumento a la corrupción, ver P. McCully, Silenced Rivers: The Ecology and Politics of Large Dains, London, Zed Books, 1996.

${ }^{45}$ C. Sánchez Bonifato, "Paraguay no quiere quedar fuera del reparto de Yacyretá7", La Nación, 10.5.99.

Respuesta del nuevo presidente paraguayo Luís Angel González Macchi a la pregunta de un periodista de Noticias: "Oviedo no controla a la mafia, Oviedo es la mafia". Noticias, 3.4.1999.
} 


\section{EL AMIGO DEL PODER}

Para continuar con los amigos del poder, cuando, el ministro de la Economía Domingo Cavallo denunciaba, con "estruendo", durante 11 horas en el Congreso el 23 de agosto de 1995, la mafia incrustada en el poder, hacía referencia al empresario Alfredo Yabrán (Círculo I de los medios de Negocios) y a su red en el entorno del presidente Menem. ${ }^{47}$ El asunto Yabrán tomó una amplitud considerable y terminó con el suicidio del hombre de negocios en 1998. Muy discretamente, y apenas conocido del público, Yabrán había hecho fortuna en los servicios de correo privado, de la manera como se practicaba en esta época: por acuerdos de monopolios sectoriales, sobrefacturación de estos servicios al Estado, fraude fiscal, manipulación contable, corrupción, asociación con delincuentes y violencia física.

Con el inicio de los años 70, empezó también la competencia por el monopolio del negocio postal. Yabrán y algunos empresarios nacionales, comienzan a distribuir envíos de documentos entre bancos, y esto con el acuerdo de la empresa estatal Encotel, quién percibía un porcentaje sobre cada envío, en razón de que continuaba con el control de la actividad. Poco a poco, Yabrán, encontró los medios para acaparar el negocio. En efecto, su empresa Osaca, "acabó" con sus competidores, utilizando entre otros medios, la exclusión de anuncios de litigio, gracias a la complicidad oficial, la desaparición de bolsas de correo, amenazas y violencias físicas. Luego, se las arregló, mediante gestiones políticas, para que Encotel se retirara cada vez más del mercado. Finalmente asegura a Osaca una posición dominante en el sector y consolida sus empresas "tapaderas", las cuales esconden negocios dudosos. Y como siempre en estos casos, el resultado afecta negativamente al ciudadano, los servicios postales costarán en promedio, cinco a diez veces el precio pagado en el extranjero.

Bajo el gobierno de Carlos Menem, estos negocios de Yabrán prosperaron como nunca, logró ubicar sus hombres de confianza a la cabeza de Encotel, obteniendo una inmunidad aduanera aeroportuaria para Osaca (lo que abría la vía a todos los

\footnotetext{
${ }^{47}$ Esta parte está basada en las fuentes siguientes: D. Cavailo, El peso de la verdad: un impulso a la transparencia en la Argentina de los 90, Buenos Aires, Ed. Planeta, 1997; G. Cherashny, Menem, Yabrán. Cavallo: final abierto, Buenos Aires. Ed. Solaris. 1997; A. F. Llórente y O. Balmaceda, El caso Cabezas. Buenos Aires. Ed. Planeta, 1997: F. Caviglia y C. Sanz, La larga sombra de Yabrán, Buenos Aires, Ed. Sudamericana, 1998: así como la revista Noticias, y los diarios Página 12 y La Nación.
} 
tráficos), se diversificó en una multitud de actividades, entre las cuales se cuenta el transporte aéreo, los servicios aeroportuarios, los servicios de seguridad en asociación con antiguos militares, las inversiones inmobiliarias en Pinamar, una estación balnearia a la moda. Todo esto le permitió prepararse para la compra de la empresa postal pública, en curso de privatización. ${ }^{48}$ Asegurándose numerosas amistades al interior del gobierno, Alfredo Yabrán, tenía un acceso directo al poder ejecutivo, incluyendo al mismo presidente. Es con ocasión del proceso de privatización de Encotel que Domingo Cavallo entra en conflicto con Yabrán, en efecto, el primero ya estaba al corriente de las quejas de otros empresarios que denunciaban la monopolización del sector postal. Desde entonces se entró en una guerra abierta, Cavallo, denunció, con un enorme ruido, la mafia operando al interior del poder y trataba de descartelizar el sector postal. Yabrán, por su parte, recurrió a sus amigos para hacer un frente contra Cavallo y amenazó físicamente a aquellos que se interpusieran en su camino.

Dos eventos marcaron la guerra entre los dos hombres. La renuncia de Domingo Cavallo de su puesto de ministro de la economía y el asesinato de reportero -fotógrafo José Luis Cabezas. En 1996, Cavallo estaba en una postura cada vez más difícil al interior del gabinete: algunos de sus allegados estaban inmiscuidos en un enorme fraude (sobornos de más de 37 millones de dólares ligados a la compra de computadoras IBM para el Banco Público de la Nación) y el ministro entró en conflicto con numerosos amigos del poder por cuestiones ligadas a la evasión fiscal. Además Carlos Menem nunca había verdaderamente soportado el tener que compartir el poder, en consecuencia, desde su reelección de 1995, decidió desembarazarse del ministro quien no era de su simpatía: muy serio, muy ambicioso, era un estorbo para muchos de sus amigos, en particular Yabrán; Pero Cavallo simpatizaba a los socios capitalistas argentinos y los grandes empresarios nacionales y su partida, ocasionaría una crisis económica, puesto que era considerado como el artesano del "milagro económico argentino". En ese sentido, el objetivo del presidente era el de encontrar un reemplazo creíble para el sector económico, cualidades que se encontraban en la persona de Roque Fernández, ultra ortodoxo presidente del Banco Central y doctor en economía de Chicago, Fernández es nombrado ministro el 26 de julio de 1996. Yabrán, había en apariencia ganado la guerra.

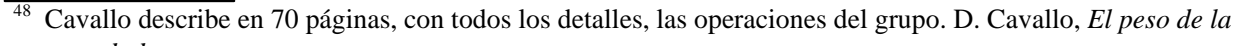
verdad.
} 
Pero un nuevo episodio vino a complicar las cosas: el asesinato, en condiciones horribles, de José Luis Cabezas, empleado de la revista Noticias y quien desde hacía algún tiempo realizaba una serie de reportajes sobre las actividades de Yabrán en la estación balnearia de Pinamar. El había logrado fotografiar al empresario y la revista publicó las fotos en 1995, lo que provocó la furia del poderoso Yabrán, el cual, gracias a su poder logró que el asesinato de Cabezas, fuera atribuido a una banda de traficantes de cocaína, en enero de 1997. Después, ante las dudas y sobretodo con el visto bueno de Eduardo Duhalde, gobernador de la provincia de Buenos Aires, competidor de Carlos Menem al interior del partido peronista y enemigo de Yabrán, la investigación fue retomada por un juez de instrucción, estimulada por el ensañamiento de la revistaNoticias, Se comienza por los medios policiacos de Pinamar, donde se descubrió que los primeros investigadores habían hecho todo lo que estaba en sus manos para desaparecer las pruebas que demostraban que sus policías estaban a la cabeza de una verdadera organización del crimen de la cual hacían parte los asesinos de Cabezas. Además todas las pistas conducían a Yabrán, quien rápidamente fue calificado de autor intelectual del crimen. Acostumbrado a la violencia, él había, aparentemente decidido hacer pagar a Cabezas su ensañamiento para investigar sobre sus asuntos y de paso enviar un mensaje "mafioso" a la prensa y a sus amigos.

Al inicio del año 1998, mientras que su imperio y sus intrigas ocupaban las columnas de los periódicos, la investigación judicial acumulaba pruebas en su contra, los amigos políticos del empresario, negaban conocerlo y apenas si podían acordarse de su nombre. Misteriosamente, Alfredo Yabrán se suicidó en junio de 1998, poniendo fin a la investigación sobre el crimen de Cabezas y aliviando sin ninguna duda, a los ex amigos del poder.

\section{LOS CONTRA PODERES MANIATADOS}

Estas situaciones no hubieran sido posibles si los contra poderes inscritos en una constitución inspirada en la de los Estados Unidos, funcionaran adecuadamente. Alejándose del ideal de equilibrio de poderes defendido por Tocqueville, el ejecutivo llevó una campaña sistemática de reserva sobre tutela de estos otros poderes, lo que permitió a la corrupción tomar proporciones sin precedentes y garantizar la impunidad casi completa de aquellos que participan en ella. 
El poder judicial se encontró en el centro de esta estrategia de cierre de posibilidades del contra poder. La Corte Suprema de Justicia representa, en semejanza al sistema político de los Estados Unidos, la última instancia de arbitraje de la legalidad en Argentina. Las tentaciones de influenciar las decisiones no han faltado nunca. Los gobiernos de facto que ha conocido el país, han forzado su propio reconocimiento por la Corte $(1930,1943,1962)$ y han disuelto esta última en su conjunto (1955,1966,1976). El gobierno democrático de Menem mantuvo esta perspectiva. Convencido desde su llegada al poder de que su control era una garantía para implementar su programa político, Menem hizo aumentar el número de jueces de cinco a nueve, nombrando jueces conocidos por ser favorables al gobierno para llenar los nuevos puestos. Infiltrada por los amigos del presidente, la Corte perdió su legitimidad por ser sensible a manipulaciones del poder político y por la implicación de varios de sus jueces en asuntos dudosos. ${ }^{49}$

Las instancias superiores del poder judicial fueron, igualmente objeto de una estrategia activa de embargo. Poco después de su llegada al poder, Menem hizo aumentar el número de jueces en los tribunales federales de seis a doce y el número de procuradores en dichos tribunales de doce a veinticuatro, las personas nombradas, eran, por supuesto, jueces "amigos". Por otro lado, el gobierno procuró disolver o desmantelar aquellos organismos judiciales que no satisfacían sus necesidades políticas: "Así quedaron en el camino el Tribunal de Cuentas y la Fiscalía Nacional de Investigaciones Administrativas". ${ }^{50}$ En general, los jueces se reparten en tres categorías: si son independientes, siguiendo el viejo adagio promover para remover, reciben una "promoción" con la cual son desplazados administrativamente a expedientes menos molestos, si son prudentes, son objeto de presiones y si son "amigos", no es necesario darles instrucciones en cuanto a la conducta a seguir. Así, los "negocios" son confiados a los jueces bajo la influencia del ejecutivo. La magnitud de esta impunidad, no le permite pasar desapercibida en el aparato judicial: un número determinado de jueces se han venido especializando en proteger a los altos funcionarios y diversos delincuentes, a cambio de especies contantes y sonantes.

\footnotetext{
$\overline{49}$ H. Verbitsky, Hacer la corle: la construcción de un poder absoluto sin justicia ni control. Buenos Aires, Ed. Planeta, 1993

${ }^{50}$ G. Beliz, "Corrupción: ¿El fin de la política?", G. Beliz (comp.), No robarás, p. 147.
} 
El jefe de orquesta de esta estrategia ha sido Carlos Vladimiro Corach (Circulo I Amigos), hombre clave de la segunda presidencia de Carlos Menem, secretario legal y técnico de la presidencia (encargado de la agenda y portavoz del presidente) y después ministro del Interior. Ex profesor de derecho en La Universidad de Buenos Aires y abogado, su recorrido político pasa de la Unión Cívica Radical intransigente de Frondizi en los años 1960 al peronismo de Cámpora en 1973, y después a la Renovación Peronista de Cañero en 1984. Sus responsabilidades reales superaron ampliamente sus funciones formales. Actuaba en la práctica como jefe de gabinete y secretario general del Partido justicialista. Corach mantenía un vínculo estrecho con ciertos dirigentes radicales, con los parlamentarios, con la justicia, con los sindicatos y con los gobernadores provinciales Su ministerio le permitía controlar gastos de más de dos mil millones de dólares, entre los cuales los aportes del Tesoro a las provincias, la policía federal, la guardia civil, y mas de 65.000 funcionarios.

Los Aportes del Tesoro Nacional (ATN), que representaban 70 millones de dólares en 1990, se elevaban en 1998 a alrededor de 350 millones de dólares. Destinados según la ley a satisfacer las necesidades extraordinarias de las provincias, (situación de urgencia o desequilibrios financieros) estos fondos se gastan según la buena voluntad de los círculos de amigos en cuestión, recompensando las filiares del régimen. Distribuidos sin tener en cuenta la importancia demográfica de las provincias o sus necesidades, están además ligados a empresas bien precisas que responden a licitaciones amañadas y sobrefacturadas, sumas que retornaban a veces hacia el partido en el poder para financiar sus campañas electorales ${ }^{51}$. Desde 1991, entre 30 y 40\% de estos fondos fueron a la Rioja, la minúscula provincia de origen de Carlos Menem, pobre, pero en todo caso lejos de ser la única en tal situación, cuyas cuentas son precarias. A mediados de 1999, los partidos de oposición y de la oposición al interior del Partido Justicialista, pidieron una investigación parlamentaria sobre la utilización de estos fondos por Corach.

Extremadamente impopular entre la población en general, ${ }^{52}$ Corach figuraba en buen puesto en la lista de enemigos de Domingo Cavallo, quien le ha consagrado una parte importante de su libro El peso de la verdad. Cavallo acusa a Corach

51 M.F. Villoso, "En el Senado quieren citar a Corach". La Nación. 20.4.99. H. Verbitsky, "El ilustrativo escándalo de los Aportes del Tesoro, atados a contratos con empresas amigas: Corach en la Mecca", Página 12, 7.9.97.

52 Noticias, 11.7.98, citando una serie de encuestas. 
de haber utilizado sus funciones para organizar la protección de diversos delincuentes por parte de la justicia, en particular Alfredo Yabrán. Expone así las diferentes maniobras consistentes en hacer nombrar, en asociación con Elias Jassan, ministro de la Justicia, en diversos puestos a jueces "amigos". De igual manera afirma, en una anécdota que posteriormente sería celebre, que Corach ha dado una lista de jueces amigos del régimen, confirmando sus sospechas. ${ }^{53}$ Frente a las denuncias de Cavallo, la venganza de Corach fue la de hacer que varios jueces abrieran investigaciones concernientes a este antiguo ministro de la Economía, esencialmente destinadas a intimidarlo o a ensuciar su reputación, aunque ninguna de ellas dio lugar a una condena.

El Congreso ha sido en general considerado más como una cámara de registro de las decisiones del ejecutivo que como un lugar de iniciación y de debate de las leyes. El Ejecutivo ha gobernado prácticamente por decreto, más de 250 durante 10 años, o sea más que todos los decretos de los gobiernos desde la Constitución de 1853, una práctica explícitamente prohibida por esta constitución (Art. 99.3), la cual precisa que la emisión de decretos no es legal, sino en casos de urgencia y de circunstancias excepcionales. El gobierno por supuesto ha tenido una interpretación particular de este artículo y ha impuesto esta práctica por su mayoría en el Congreso y su control de la Corte Suprema.

Frente a la evasión fiscal que oscila entre 15 y 20 mil millones de dólares por año, (los Argentinos tienen la tendencia a considerarla como un derecho y un deber), los sistemas de control administrativo han sido parcialmente reforzados, pero ellos también han conocido límites políticos. La Dirección General del Impuesto (DGI) creó un equipo de auditores de alto nivel, quienes estudiaron mas de 2.000 expedientes en cuatro años, descubriendo más de 8 mil millones de dólares de fraude. Denominados "los Intocables" por la prensa, este equipo, muy eficaz, fue desmantelado por haber revelado numerosos negocios que comprometían a amigos del gobierno, por ejemplo el negocio de los Macri, el clan automotriz estrechamente vinculado al presidente Menem. El ministro de la Economía, Cavallo, en su origen participante de este equipo de investigación, se encontró, entonces en conflicto

\footnotetext{
Cavallo relata el siguiente incidente: "Así fue como [Corach] explicó que las designaciones de los jueces en lo penal económico y los jueces federales (...) se habían realizado bajo un criterio similar. En todos los casos, tenía que haber un garante de la conducción política del juez respectivo. De pronto, Corach tomó un servilleta de papel y empezó a escribir los nombres de los jueces que eran controlados desde el poder político.", D. Cavallo, El Peso de ; a verdad, p. 261.
} 
directo con el sector político del Partido justicialista a causa de los celos de la DGI. Todo esto le costó un difícil conflicto con el mismo presidente y tuvo que retroceder, abandonando los "intocables", quienes a su turno, presentaron su renuncia $^{54}$. La apertura económica y la caza fiscal tienen sus límites, impuestos por los negocios de la "corte". A pesar de todo esto, ciertos allegados a Menem, por citar algunos ejemplos, Ornar Fassi Lavalle (Circulo II Amigos), ex secretario de turismo o José Alberto Samid (Circulo II Amigos), industrial de la carne y ex diputado peronista, se vieron implicados en acusaciones o condenados por fraude fiscal por la justicia. Chivos expiatorios, sobresalto ético?

Existían, ciertamente, discursos de oposición los cuales se expresan en los medios de comunicación. Ante este hecho el poder tendía a reaccionar de dos maneras, sea por control directo o indirecto. El control de la prensa se ejerció a partir de una gama de medios, yendo de una ley contra la difamación totalmente desproporcionada (el gobierno retrocedió), al boicot publicitario de uno de los medios, pasando por el maltrato físico de los periodistas excesivamente curiosos realizados por misteriosos desconocidos. Las tentativas de maniatar la prensa fracasaron cuando fueron directas, pero han tenido éxito parcial, cuando se utilizaron procedimientos indirectos, en particular las avalanchas de denuncias penales. $^{55}$

El sindicalismo, contra poder tradicional en Argentina, perdió su fuerza por una mezcla de tres factores: descrédito político, disminución del número de sus miembros y control del ejecutivo peronista del aparato sindical. La policía se preocupa sobretodo de hacer negocios. Los militares vieron su rol reducido a casi nada entre otras cosas por la reducción del presupuesto y el nuevo dato geopolítico latinoamericano. Y el aparato de seguridad en general, por ejemplo los diversos servicios secretos, han sido controlados por la puesta en disposición del Ejecutivo, de sumas importantes de las cuales no debe dar cuenta, administradas en particular por Carlos Corach.

\footnotetext{
${ }^{54}$ Noticias, "Intocables: nos volvimos incontrolables", 11-02-1996.

${ }^{55}$ Un ejemplo característico es el de Horacio Verbitsky. quien testimonia en el Buenos Aires Herald, (15-09-1992): "I am 50 years old. have been a journalist for 32 of those years, and until the publication of Robo para la corona I had never been sentenced by a court. Forly-five days after the publication of the book I had my first sentence, a one-month suspended sentence, from the Supreme Court of Justice, the same court described as having being taken over by President Carlos Menem in chapter four of that book. 1 vvas found guilty of contempt of authority (desacato) regarding one of the members of that court. That same vveek, in February 1992. half a dozen government offícials opened charges against me. some for contempt of authority. others for perjury. becausc of the book. Thís was part of a strategy to limit my freedom of movement and with the purpose of forcing me to leave the country".
} 


\section{CONCLUSIÓN}

La corrupción impone un costo suplementario a la actividad económica así como una distorsión de los mecanismos de precio, desviando los recursos hacia actividades improductivas y debilitando la competencia de instituciones del Estado y su legitimidad. Así mismo, se puede pensar que ella no favorece tampoco el desarrollo de una sociedad justa y que la clase política actual constituye un triste ejemplo para los jóvenes. A largo plazo, el costo social deberá, seguramente ser muy elevado.

Un comentarista político conocido, James Neilson, habló de "colapso ético". La clase política argentina ha practicado abiertamente y con eficacia todas las formas de corrupción sin vergüenza, en un país donde 15\% de la población es desempleada y un tercio en una situación económica precaria.

A pesar de esta nota pesimista, el "embalse de impunidad" que protegía los miembros del gobierno Menem comenzó a agrietarse, en particular con las disensiones políticas causadas por el enfoque de las elecciones presidenciales de 1999: los políticos peronistas que proyectaban un porvenir tomaron su distancia de los colegas más comprometidos, lo que abrió posibilidades a la prensa y a la justicia. En los últimos años del régimen Menem, algunas de las personas mas cercanas se han visto inculpadas con acusaciones cada vez más precisas.

La corrupción, fenómeno recientemente señalado con el dedo por las organizaciones financieras internacionales, es uno de los principales problemas que pone enjuego el devenir político de Argentina. El eco que se le ha dado es. en consecuencia, amplio y fue utilizado como caballo de batalla por la coalición de oposición, la Alianza (Partido Radical y Frepaso), amenazando con llevar ante la justicia a Carlos Menem y a un grupo de personas cercanas a él, una vez las elecciones se hubieran llevado a cabo y la impunidad legal formal fuera levantada. A pesar de todo este procedimiento de denuncia y de instrumentación política, no es seguro que la Alianza esté en la posibilidad de investigar a fondo la corrupción. Primero, varios funcionarios o políticos radicales y varias personas alrededor de Fernando de la Rúa, el nuevo presidente, han sido mencionados 
en varios escándalos ${ }^{56}$. Segundo, los peronistas son mayoría en el Senado hasta el año 2001, y controlan 14 de las 24 provincias contra 8 para la Alianza. Igualmente, los sindicatos continúan siendo peronistas, los jueces nombrados por el gobierno Menem desempeñan todavía sus funciones políticas. Tercero, la Alianza se mantiene como una coalición caracterizada por importantes divisiones políticas. En este sentido gobernar en situación de abierta hostilidad contra los peronistas podría paralizar la acción gubernamental de Femando de la Rúa. A pesar de una intención claramente manifestada de investigar a fondo la corrupción bajo el gobierno Menem, una inquietud muy difundida es que un pacto informal de no agresión sea concluido entre los principales partidos políticos.

Los creyentes de la libre empresa notarán, de otra parte, con deleite, el desarrollo fulgurante de las consultorías privadas en materia de lucha anticorrupción. Por ejemplo el ex procurador en el proceso de lajunta militar, Luis Moreno Ocampo, se convirtió en un especialista en la materia y puso en marcha un gabinete cuyos servicios son fuertemente demandados entre otros por las empresas del Estado.

Finalmente, sin ir hasta hablar de una democracia bajo secuestro como lo han afirmado ciertos observadores, hay que reconocer que nos encontramos muy alejados del ideal democrático hecho del equilibrio de poderes, de alternancia, de respeto de minorías y de transparencia. A pesar de que la liberalización económica, debía poner fin al Estado depredador, este ejemplo, ha puesto en evidencia que la corrupción más "desvergonzada" puede cohabitar con el liberalismo sin freno.

Los restos de caudillismo y de clientelismo, influencian la gestión económica de Argentina. Todo el autoritarismo en la sociedad argentina no desapareció con el último régimen militar y los procedimientos ilustran bien la paradoja, entre la necesidad de un Estado fuerte para la puesta en marcha de un neo-liberalismo y aquella del desmantelamiento del Estado conforme a los preceptos de este modelo. A condición de satisfacer ciertas normas internacionales, aquellas de Bretton Woods y de permitir una relativamente buena marcha de los asuntos domésticos, los "negociantes" políticos han sabido preservar las zonas de protección, al menos lo suficiente para enriquecerse.

\footnotetext{
En particular cuando éste ejercía como intendente del Gobierno autónomo de la ciudad de Buenos Aires: el escribano general del Gobierno de la Ciudad de Buenos Aires, Jorge Gómez, La Nación 2.10.98; el director general de Servicios Públicos del gobierno porteño, Horacio Garlan, La Nación 12.7.98.
} 